\title{
Elementos de la Filosofía de la Liberación Para Una Recomprensión Descolonial de Derechos Humanos
}

\section{Alejandro Rosillo Martínez}

Doctor en el Programa de Estudios Avanzados en Derechos Humanos de la Universidad Carlos III de Madrid, con la tesis "Los derechos humanos desde el pensamiento latinoamericano de la liberación". Master en Estudios Avanzados en Derechos Humanos de la Universidad Carlos III de Madrid, con la tesina "La filosofía de la realidad histórica de Ignacio Ellacuría y los derechos humanos". Premio Extraordinario del Máster Universitario en Estudios Avanzados en Derecho Humanos, correspondiente a la promoción 2007/2008, otorgado por resolución de la Vicerrectora de Postgrado y Calidad, de la Universidad Carlos III de Madrid. Abogado. Facultad de Derecho de la Universidad Autónoma de San Luis Potosí. arosillo@gmail.com

\section{Resumen:}

A partir de la crítica a la Modernidad que realiza el pensamiento descolonial, se asume que el discurso de derechos humanos es parte del sistema moderno/colonial. En efecto, se entiende que si bien se les ha dado un uso dentro de luchas de emancipación (Modernidad) también se han utilizado para justificar procesos de colonización y han acompañado a la colonialidad del poder. No obstante, se reconoce el potencial descolonizante de su discurso, y por eso se analizan algunas categorías de la Filosofía de la Liberación que pueden contribuir en una fundamentación de derechos humanos que vaya en camino hacia su uso descolonial.

Palabras-clave: Colonialidad del poder. Derechos humanos. Liberación. Interculturalidad. DescoIonización. 


\title{
ELEMENTS OF THE PHILOSOPHY OF LIBERATION FOR HUMAN RIGHTS: Towards a de-colonial re-comprehension of Human Rights
}

\begin{abstract}
:
Since the critique of Modernity that the de-colonial thinking operates, it is assumed that the discourse of human rights is part of the modern/colonial system. Indeed, it is understood that although they have been given an application in struggles for emancipation (Modernity), they have also been used to justify colonization processes have accompanied the coloniality of power. However, one recognizes the potential of de-colonizing speech, and that is the reason why some categories of Philosophy of Liberation that can contribute to a foundation for human rights that run to their de-colonial use are analyzed.
\end{abstract}

Keywords: Coloniality of power. Human rights. Liberation. Interculturalism. De-colonization.

\section{SUMÁRIO}

1. Introducción. 2. Filosofía de la Liberación y Descolonialidad. 2.1. La Alteridad. 2.2. La Praxis. 2.3. La Producción y Reproducción de Vida. 3. Conclusión. 4 Referencias. 


\section{INTRODUCCIÓN}

El pensamiento descolonial significa un reto para la teoría de los derechos humanos, ya que en cuanto a la visión dominante, ellos son un producto de la Modernidad. En este sentido, el análisis que se realiza del sistema moderno/colonial cuestiona de raíz el fundamento de los derechos humanos: su universalidad, su monoculturalidad, su eurocentrismo, su individualismo, etc. Por otro lado -se puede sostener- esta crítica pasa por alto el potencial liberador del discurso de derechos humanos; que no se toman en cuenta las posibilidades reales que los derechos humanos han tenido cuando son utilizados y asumidos por movimientos sociales o sectores marginados que, en muchas ocasiones, son los mismos sujetos que sufren de diversas formas de colonialidad.

Ahora bien, si bien existe un uso liberador de derechos humanos que ciertas subjetividades emergentes realizan, esto no deja a un lado que el discurso de derechos humanos, como estrategia política y jurídica de la Modernidad, esté afectado de colonialidad, y que, en consecuencia, puedan constituirse en instrumentos de dominación. Para Quijano, la colonialidad "es uno de los elementos constitutivos y específicos del patrón mundial del poder capitalista” (Quijano, 2000, p. 93). Es decir, se trata de un concepto que si bien guarda relación, es diferente al concepto de "colonialismo". La colonialidad significa que, a partir de 1492, se inició un proceso donde la división internacional del trabajo se realizó entre periferias y centros, y con un gran énfasis la jerarquización étnico-racial de las poblaciones. Este proceso no ha concluido con la finalización formal del régimen político del colonialismo, sino continúa y estamos en una transición hacia la colonialidad global.

En este sentido, el discurso eurocentrado de derechos humanos ha sido un componente que ha funcionado para la colonialidad del poder, del saber, del ser y del hacer. La manera en que concretiza la comprensión de dignidad humana y, en especial, las formas y mecanismos de protegerla, 
es en variadas ocasiones una forma de ejercer la colonialidad. De ahí que consideremos necesario repensar los derechos humanos para lograr su descolonización. $\mathrm{O}$ en otras palabras, desarrollar una teoría crítica que dé mejor cuenta a las prácticas liberadoras que encarnan, apropian y transforman el discurso de derechos humanos.

Hemos de reconocer que la construcción de una teoría crítica de derechos humanos, desde la perspectiva descolonizadora, es una tarea ardua y de largo alcance. Por el momento, en las siguientes líneas, reflexionamos sobre algunos aportes que la Filosofía de la Liberación (FL) puede realizar a esta labor. Básicamente nos centraremos en tres conceptos que han de tomarse en cuenta para hablar de una fundamentación de derechos humanos: la alteridad, la praxis y el sujeto vivo necesitado.

\section{FILOSOFÍA DE LA LIBERACIÓN Y DESCOLONIALIDAD}

El tema de la descolonización y los derechos humanos ha estado potencialmente presente en el pensamiento de la liberación. Una muestra es un artículo de Ignacio Ellacuría escrito a petición de una revista francesa, donde se le plantea la relación de los derechos humanos con las luchas de los pueblos indígenas. Su respuesta la realizó dentro del marco de análisis que le daban las categorías "mayorías populares” y "realidad histórica” pero enriquecidas con el contenido intercultural. En efecto, propone la construcción de una "teoría revolucionaria de los derechos humanos" que parta de las luchas de las mayorías populares por transformar y que dé más de sí la realidad histórica, con el fin de superar las situaciones de injusticia.

En este contexto, Ellacuría comprende a los pueblos indígenas como parte de esas mayorías populares, pero añade - de cierta forma - la cuestión de la “colonialidad del poder, del ser y del saber”. De ahí que establezca la necesidad de la autonomía indígena, como parte de un derecho a la insurrección o revolución, en los siguientes términos: 
Una de las formas típicas de esta injustica es la de la heterodeterminación, la de ser forzados a determinar la existencia individual y colectiva por lo que otras quieren. De ahí que el derecho de insurrección se pueda afirmar positivamente como derecho de autodeterminación, pero de autodeterminación sobre todo de quienes han sido forzados secularmente a heterodeterminarse, los secularmente hterodeterminados (Ellacuría, 2012, p. 296).

Reconoce la importancia de no desperdiciar la experiencia histórica de los pueblos indígenas para poder reconstruir las luchas por la dignidad humana y lograr generar una nueva comprensión de los derechos humanos. Siguiendo esta línea, sostenemos que a partir de la Filosofía de la Liberación (FL) se puede proponer un camino para una fundamentación de derechos humanos que asuma la descolonialización.

\subsection{La alteridad}

La FL, aún cuando es crítica de la Modernidad, no renuncia a la subjetividad. Para los procesos de liberación es importante que la víctima, el pobre y el oprimido se constituyan en sujetos de su propia historia. Sin embargo, la FL no fundamenta derechos humanos en el sujeto abstracto de la Modernidad, ni en el individuo egoísta que sólo busca su propio interés. La autonomía del sujeto no es sinónimo de la subjetividad moderna que inicia los procesos de derechos humanos. Esto porque el sujeto abstracto de la Modernidad se constituye como una Totalidad excluyente, no abierta a la proximidad, ni a la exterioridad del Otro. Además, como señala Hinkelammert, la moderna sociedad occidental más que antropocéntrica es mercadocéntrica (Hinkelarmmert, 2005); ha colocado el mercado como un supuesto orden natural, y la legitimidad y validez de las instituciones están en función de que permitan el libre desenvolvimiento de las leyes de mercado. Por eso, la visión del sujeto y de la subjetividad de la Modernidad, iniciada con Descartes, terminó ligándose al dominio de la naturaleza 
y de la realidad social a través del capitalismo. Se trata de una concepción egocentrista del ser humano, que sacraliza al individuo como propietario que fomenta la enajenación y mercantilización de todas las facetas de la vida humana. Reducir la dimensión subjetiva del ser humano a la subjetividad individualista de la Modernidad hegemónica significa promover un desperdicio de la experiencia. Desde otras culturas, la subjetividad se ha construido de manera distinta, y en diversas ocasiones de forma comunitaria.

La subjetividad debe constituirse en el encuentro con el otro. Como es bien sabido, es Enrique Dussel quien, partiendo de la filosofía de Emmanuel Levinás, ha introducido la alteridad como un elemento fundamental de la FL. Por eso, se habla de una FL concebida como una metafísica de la alteridad o una filosofía de la alteridad ética (García Ruiz, 2003; Salamanca, 2003). A partir de ahí, se trataría de constituir subjetividades de personas y de pueblos; es decir, tanto subjetividades personales como subjetividades colectivas.

Del conjunto de categorías que Dussel aporta a la FL, algunas de ellas tienen relación con una fundamentación de derechos humanos desde la alteridad y, además, autores juristas cercanos a los movimientos de liberación las han tomado en cuenta para la construcción de su pensamiento jurídico (De la Torre; Rangel, 2007, p. 139-159). Estas categorías son la proximidad, la totalidad, las mediaciones, la libertad situada, la exterioridad y la enajenación.

Dussel afirma que la exterioridad es la categoría más importante para la FL, y que posibilita realizar un discurso nuevo. Es decir, la exterioridad marca la diferencia de la FL con las filosofías del centro que usan también las otras categorías. Posibilita un discurso nuevo porque hace viable fijarse en la realidad de los pueblos periféricos: "Es la novedad de nuestros pueblos lo que se debe reflejar como novedad filosófica y no a la inversa” (Dussel, 1996, p. 55). La exterioridad parte del hecho de que en 
el conjunto de todos los entes, sobresale uno, distinto a todos los demás: el rostro de los otros seres humanos. Alejados de la proximidad, consumidos por la proxemia - donde aún el rostro humano es asumido como una cosa-sentido, como un ente más -, la presencia de este rostro nos recuerda la necesidad de aquélla. El ser humano como ente es parte de la totalidad, de los sistemas, pero la emergencia de su rostro nos vuelve a enfrentar a la proximidad; es cuando el otro se nos revela en toda su exterioridad (Dussel, 1996, p. 56).

Pero también es importante considerar la categoría de alienación, que se da cuando se le niega al otro su calidad de otro. La totalidad, el sistema, tiende a totalizarse, a autocentrarse; busca eternizar su estructura presente y a devorar intrasistémicamente a toda exterioridad posible (Dussel, 1996, p. 70). Entonces para el sistema el otro aparece como algo diferente, que pone en peligro la unidad de "lo mismo". En efecto, al otro en tiempo de peligro se le transforma gracias a la ideologización en "el enemigo".

Estas categorías nos posibilitan establecer un fundamento de derechos humanos desde la alteridad, desde el encuentro con el otro. A diferencia de los fundamentos hegemónicos de derechos humanos basados en una subjetividad del individuo, que finalmente son parte de la totalidad, del sistema dominante, la FL propone un fundamento en la alteridad, desde una subjetividad abierta al otro y no cerrada en la mismidad. En este contexto, la subjetividad moderna es parte de la totalidad que sólo reconoce derechos a los mismos, ${ }^{1}$ no al inequívocamente otro, al que por la totalidad es considerado extraño, ajeno y hasta peligroso al sistema. A ese otro, al contrario, aunque exija la satisfacción de las mismas necesidades que los mismos, es catalogado de delincuente; por eso, se criminalizan la protesta

${ }^{1}$ Esos mismos, esos que reafirman la mismidad del sistema, son los que concretizan al ser humano abstracto, a ese ser humano que se considera "sujeto universal de derechos", es decir, el varón, blanco, burgués, adinerado, occidental, etc. 
y las luchas sociales y las praxis de liberación se reprimen (ellas son finalmente los medios en que los otros emergen para romper la alienación a la que son sometidos). En efecto, la comprensión de derechos humanos efectuada sólo desde el individuo está marcada por un reduccionismo monocultural e historicista.

Sin negar la subjetividad como elemento de una fundamentación de derechos humanos, es imprescindible abrirla a la pluriculturalidad y a las luchas históricas llevadas a cabo por los diversos pueblos oprimidos del planeta; se trataría de un sujeto inter-subjetivo, comunitario, que sea el sujeto de derechos humanos como praxis de liberación. Es lo que propone la FL a partir de una metafísica de la alteridad, que se concretiza en comprender a la ética, a la responsabilidad por el otro, como el inicio de toda filosofía. Esta ética es una ética de la solidaridad que tiene sus consecuencias para la construcción de una juridicidad alternativa, generada desde las luchas sociales (Wolkmer, 2002, p. 179-180).

La ética de la alteridad busca una apertura del sujeto que sea capaz de comprender lo nuevo de la historia que se construye desde la exterioridad. "El punto de partida es la víctima, el Otro, pero no simplemente como otra 'persona-igual' en la comunidad argumentativa, sino ética e inevitablemente (apodícticamente) como Otro en algún aspecto negado-oprimido (principium oppressionis) y afectado-excluido (principium exclusiones)" (Dussel, 1998, p. 417). Desde el otro como otro - el pobre, el oprimido, la víctima -, que es libertad incondicionada por cuanto se desprecia su exterioridad considerándola nada (como incultura, analfabetismo, barbarie, primitivismo, incivilización), es como surge en la historia lo nuevo. Por ello todo sistema futuro realmente resultante de una revolución subversiva en su sentido metafísico es analógica: semejante en algo a la anterior totalidad, pero realmente distinto. 
Todo lo anterior se realiza, se hace realidad, cuando alguien dice, por ejemplo, “i[t]engo hambre, necesito alimento!” (Dussel, 1998, p. 524). El hambre del pobre es consecuencia de un sistema injusto, y en su situación de víctima no tiene lugar dentro del sistema. No tiene lugar por ser negatividad, por sufrir falta-de, por ser no-ente en el mundo. Pero fundamentalmente está fuera porque saciar estructuralmente el hambre del pobre es cambiar radicalmente el sistema. En efecto, derechos humanos fundamentados desde la alteridad han de comprenderse en herramientas de lucha de quienes son víctimas del sistema, y por eso, más que elementos conservadores del sistema han de ser subversivos, transformadores, revolucionarios. El cara-a-cara con el otro inequívoco obliga a repensar constantemente derechos humanos, pues los derechos del otro no son parte del sistema (Dussel, 1996, p. 59).

La FL propone recuperar al ser humano como se hace presente en la realidad, como ser corporal, como sujeto viviente frente a otros que también se hacen presentes como seres corporales y sujetos vivientes; es una relación de cuerpo a cuerpo, de cara-a-cara. La pregunta clave de este sujeto no es "si existo" sino "puedo seguir existiendo". Se trata de responderse por las condiciones de posibilidad de vivir cómo ser corporal, como ser viviente.

La demanda de la recuperación del sujeto, de la vida humana concreta, de la vida para todos, en las instituciones sociales y en las construcciones culturales, es la demanda más urgente del mundo de hoy. Para esto, derechos humanos es, sin duda, una herramienta importante, pero fundamentado en un sujeto inter-subjetivo. Y esto tiene que ver con la vuelta, en palabras de nuestro autor, al sujeto reprimido y al bien común.

\subsection{La praxis}

La FL no se comprende sólo como una ética de la alteridad, sino también puede entenderse como una filosofía de la praxis. Diversos autores - por ejemplo, Ellacuría, Dussel y Hinkelammert - abordan en su refle- 
xión las diversas formas de praxis. De una u otra forma, buscan encontrar sus características para poder considerarla como una praxis de liberación. Si bien parten del análisis de la praxis humana en general, coinciden en señalar que no toda praxis es liberadora, sino que existen unas opresoras, homicidas y alienantes. En este sentido, derechos humanos como realidad histórica está afectada por esta ambivalencia de la praxis; derechos humanos bien pueden ser instrumentos de ideologizaciones funcionales a prácticas opresoras o herramientas para la liberación. Fundamentar derechos humanos desde la praxis significa encontrar un fundamento sociopolítico; se trata de entenderlos como herramientas de las praxis de liberación.

Ellacuría aborda la praxis desde el análisis de los elementos y dinamismos que integran la realidad histórica que van desde la materialidad hasta la dimensión personal, y desde el individuo hasta el cuerpo social. Como señala Antonio González, la praxis humana “en cuanto apropiación y transmisión tradente de posibilidades es la categoría más apropiada para comprender la originalidad de lo histórico” (González, 1999, p. 11). En diversos escritos, tanto en los de carácter político, filosófico como teológico, Ellacuría utiliza el concepto praxis, y en variadas ocasiones lo hace de manera adjetivada; así se encuentran conceptos como praxis histórica, praxis social, praxis politica, etc. Es un concepto utilizado por este autor como parte de su diálogo con el marxismo, aunque con una importante fundamentación en el pensamiento de Xavier Zubiri.

Para Ellacuría, por su carácter transformador, la praxis es el ámbito donde con mayor claridad se expresa la interacción entre el ser humano y el mundo, pues en ella las relaciones no son siempre unidireccionales sino respectivamente codeterminantes. A través de la praxis se muestra el poder creativo del ser humano. Este poder “está en estrecha relación con el grado de libertad que vaya alcanzado [el ser humano] dentro del proceso histórico" (Samour, 1999, p. 110). Si bien todo tipo de actividad humana transformadora está incluido en la reflexión filosófica de la praxis 
humana, pues ella incluye todas las formas del quehacer humano, tanto especulativas, educativas, técnicas, religiosas, etc., Ellacuría pone énfasis en las praxis históricas de liberación, es decir, en aquellas que actúan como productoras de estructuras nuevas más humanizantes. En sentido semejante, Dussel señala que la praxis de liberación “es la acción posible que transforma la realidad (subjetiva y social) teniendo como última referencia siempre a alguna víctima o comunidad de víctimas” (Dussel, 1998, p. 553).

El proceso práxico de liberación, ya en el ámbito ético y político, es principalmente dialéctico - aunque no exclusivamente - en cuanto busca negar la negación de los seres humanos, y se avance afirmando lo positivo. Un proceso que se da dentro del dinamismo histórico de la posibilitación y capacitación, por lo cual no existe ninguna garantía de triunfo. Ya se ha dicho que la realidad histórica puede ser principio de humanización y de personalización, pero también puede ser de opresión y alienación. Esto porque "la praxis histórica no es reducible ni a las leyes del mundo natural ni a los saltos dialécticos de algún presunto espíritu” (González, 1999, p. 11). A diferencia de lo que puede suceder con posturas idealistas o mecanicistas de la historia, el mal y la injusticia en la historia no pueden ser legitimados ni justificados como unas necesidades lógicas en el desarrollo de una teleología o como partes de un devenir forzoso de la historia. Más bien el mal histórico es un límite real que se presenta como un desafío a la praxis de liberación. La liberación es, entonces, un proceso a través del cual el ser humano va ejerciendo su libertad, y va haciéndose cada vez más libre gracias a su estructura de esencia abierta (Ellacuría, 2000, p. 640).

La concepción de la praxis hasta ahora analizada tiene importantes consecuencias para la fundamentación de derechos humanos, si estos se asumen como momentos de la praxis histórica de liberación. En este contexto no sería viable, y carecería de sentido, un fundamento absoluto y dogmático, desde el que se proponga un tipo de "falacia desarrollista". 
En efecto, deberán comprenderse derechos humanos desde su complejidad como momentos pertenecientes a las distintas fuerzas históricas; es decir, contemplarlos como momentos tanto jurídicos como ideológicos, sociales y políticos. Esto significaría asumir una concepción compleja de derechos humanos.

El comprender derechos humanos como momentos de la praxis histórica de liberación se constituye en un fundamento socio-histórico. Es decir, se trata de entender la praxis de liberación de los nuevos sujetos socio-históricos como fundamento de derechos humanos.

Ahora bien, la FL no sólo desarrolla la comprensión del sentido de la praxis sino también del sujeto de ella. De entrada, toda persona puede constituirse en sujeto de la praxis de liberación, ya sea en su calidad de víctima o por ser solidario con el oprimido, en cuanto realiza acciones, organiza instituciones o transforma sistemas para que las víctimas, los pobres y los oprimidos disfruten y ejerzan efectivamente derechos humanos (Dussel, 1998, p. 513). Pero el analogado principal del sujeto de la praxis de liberación es la víctima que adquiriendo consciencia de su situación, y en diálogo con otras víctimas, emprende acciones para dejar atrás, para superar, la situación que le niega las posibilidades de producir y reproducir su vida. En este sentido, Dussel afirma: "El sujeto de la praxis de liberación es el sujeto vivo, necesitado, natural, y por ello cultural, en último término la víctima, la comunidad de las víctimas y los a ella co-responsablemente articulados. El 'lugar' último, entonces, del discurso, del enunciado crítico, son las víctimas empíricas, cuyas vidas están en riesgo, descubiertas en el ‘diagrama’ del Poder por la razón estratégica” (Dussel, 1998, p. 525).

El sujeto de la praxis de liberación supone no una mera subjetividad individual sino la ya mencionada inter-subjetividad. La intersubjetividad no significa la creación de un sujeto colectivo natural, pues esto conlleva finalmente a una sustantivización indebida; los sujetos socio-históricos son fluidos y fragmentarios, aparecen y desaparecen en coyunturas bien deter- 
minadas, según las tramas sociales. Más bien significa el reconocimiento de la subjetividad de cada sujeto humano concreto, y de su encuentro con el otro, que también es sujeto, y que por sus cualidades de víctimas o solidario con ellas, se conforman en una comunidad de vida (Gallardo, 2008, p. 60). Como señala Dussel, la intersubjetividad "se constituye a partir de una cierta comunidad de vida, desde una comunidad lingüística (como mundo de la vida comunicable), desde una cierta memoria colectiva de gestas de liberación, desde necesidades y modos de consumo semejantes, desde una cultura con alguna tradición, desde proyectos históricos concretos a los que se aspira en esperanza solidaria” (Dussel, 1998, p. 525).

Por su parte, Hinkelammert resalta el carácter procesual del hacerse sujeto que, para la FL, significa la vuelta -la recuperación- del sujeto reprimido: “...el ser humano como sujeto no es una instancia individual. La intersubjetividad es una condición para que el ser humano llegue a ser sujeto. Se sabe en una red, que incluye la misma naturaleza externa al ser humano: que viva el otro, es una condición de la propia vida” (Hinkelammert, 2005, p. 495). El ser humano para vivir requiere hacerse sujeto; la vida es un llamado a constituirse como sujeto. En efecto, el ser sujeto no es un antes, un a priori del proceso, sino que resulta del mismo proceso (Hinkelammert, 2005, p. 496). Es decir, el "sujeto" no contiene un valor o una sustancia a priori, sino que depende del sentido negativo del sistema que lo hace víctima; lo que podría decirse es que ese sujeto buscará revertir su situación de víctima a través de la generación de un nuevo sistema. En efecto, para llegar a ser sujeto de la praxis de liberación es necesario efectuar una crítica autoconsciente del sistema que causa la victimización. Las víctimas han de caer en la cuenta de que no habían participado en el acuerdo originario del sistema -por utilizar expresiones de la ética del discurso-y, sobre todo, en que debido a dicho sistema no pueden producir, reproducir y desarrollar su vida (Hinkelammert, 2005, p. 495-496). 
Habíamos señalado párrafos arriba que el proceso práxico de liberación es principalmente dialéctico, aunque no exclusivamente. En cuanto a derechos humanos, la praxis de liberación se constituye, en diversas ocasiones, por el enfrentamiento de un movimiento social organizado de las víctimas y un sistema formal dominante. Se genera un conflicto ético, con consecuencias sociales y jurídicas, donde la comunidad de víctimas busca modificar las tramas sociales para lograr una transferencia de poder con el fin de satisfacer sus necesidades de vida (Gallardo, 2008, p. 44; Dussel, 1998, p. 541). Si la praxis de liberación se realiza por un sujeto inter-subjetivo, el principio normativo "crítico democrático" es parte de ella. La intersubjetividad en las luchas de liberación se basa en el consenso crítico de las víctimas. Un movimiento social basado, por ejemplo, en las decisiones de "líderes" y que no se guía por la voluntad consensada de las víctimas, terminará reproduciendo el mismo sistema que excluye a las víctimas y esos "líderes" terminarán utilizando el poder de manera fetichizada. Por eso, la intersubjetividad tiene que ver con dicho principio, que Dussel define de la siguiente manera: "El principio normativo crítico democrático apunta a promover el consenso crítico de las víctimas, por su participación real y en condiciones simétricas” (Dussel, 2006, p. 105). En efecto, al fundamentar derechos humanos en la praxis de liberación, se comprende la importancia del consenso de las víctimas para que la lucha por "nuevos derechos" signifique la creación de un nuevo sistema, que incluye la participación de los que habían sido excluidos.

De lo anterior podemos concluir que el estado no es fundamento de derechos humanos; a lo más puede ser un instrumento, un conjunto de instituciones, para hacerlos efectivos. La praxis de liberación de los pueblos es un hecho más radical que la existencia y el funcionamiento del estado (Salamanca, 2008, p. 28-34). Si se fundamenta derechos humanos en la praxis histórica de liberación se potencializa, siguiendo las categorías de Boaventura de Sousa Santos, el pilar emancipatorio de la Modernidad. En cambio, si se fundamentan en el estado, se potencializará a la larga 
uno de los pilares de control (Santos, 2009, p. 31). Por tanto, recuperando lo mejor de la Modernidad, la FL ha de insistir que derechos humanos deben conservarse como parte del pilar emancipatorio fundamentándolos en las praxis de liberación.

Los derechos humanos tienen como uno de sus fundamentos la praxis histórica de liberación, en cuanto ésta se realiza por una comunidad de víctimas -que se constituye en un sujeto intersubjetivo- que busca, al ejercer el derecho a generar derechos, subvertir el sistema que le niega la satisfacción de necesidades para la producción y reproducción de vida, y dar paso a un nuevo sistema. Esto conlleva el colocar a la praxis como el hecho más radical, que antecede al estado o a la "naturaleza humana", en cuanto a la búsqueda de fundamentos de derechos humanos. Es un fundamento no-dogmático, ni etnocéntrico, ni historicista; defiende la necesidad del sujeto, pero no del sujeto individual y abstracto de la Modernidad hegemónica, sino el sujeto intersubjetivo que se constituye a través de la voluntad de liberación de las víctimas reunidas y organizadas en comunidad.

\subsection{La producción y reproducción de vida}

La FL tiene como un tema central de su reflexión al "sujeto vivo", y en conexión con él a la satisfacción de las necesidades para la vida. La recuperación del sujeto no sólo es referida a un sujeto intersubjetivo y a un sujeto de la praxis de liberación, sino también al sujeto como sujeto vivo, como un ser corporal, por el que la satisfacción de necesidades se constituye como un hecho radical. Esto no quiere decir que el sujeto intersubjetivo y el sujeto de la praxis queden relegados a un segundo sitio, otorgándole la primacía al sujeto vivo. No se trata de jerarquizar a los "sujetos". Es decir, para que el sujeto de derechos humanos realmente sea tal, debe ser alternamente un sujeto vivo, intersubjetivo y práxico (Hinkelammert, 
2002). La ausencia de cualquiera de ellos, o la ausencia total de sujeto, significaría que la fundamentación de derechos humanos caería en alguno de los riesgos analizados al inicio de esta sección.

En virtud al sujeto vivo, la fundamentación de derechos humanos se constituye como un referente crítico del sujeto de la praxis, encaminado a responder a la interpelación que las víctimas realizan a través del sujeto intersubjetivo. Es decir, si el sujeto de la praxis dirige su actuar para lograr una liberación integral, a través de la organización y el consenso de la comunidad de víctimas que transforma el sistema a través de "nuevos derechos”, la satisfacción de necesidades para la vida es el marco material de esa praxis, de esa organización y de ese consenso entre las víctimas: "El juicio de hecho crítico (desde el marco material de la ética) se enuncia como la posibilidad de la producción, reproducción y desarrollo de la vida de los sujetos reales del sistema, y como 'medida' o criterio de los fines del mismo: si la vida no es posible, la razón instrumental que se ejerce en hacerlo imposible es éticamente perversa” (Dussel, 1998, P. 523).

El sujeto vivo evita que el sujeto de la praxis quede tan sólo en un sujeto pragmatista que aplica la razón instrumental en función del cálculo de utilidad. Esta es una forma de ejercer la razón que hace imposible la reproducción de vida, pues a la larga significa el suicidio. Hinkelammert señala que entre los siglos 14 al 16, en los inicios de la Modernidad, la racionalidad medio-fin, que es la racionalidad concebida a partir del individuo y se caracteriza por ser la racionalidad económica hegemónica, se impone -o se pretende imponer- a la sociedad entera (Hinkelammert, 2005, p. 19-23). Es una racionalidad que atenta contra la vida y niega derechos humanos, y por eso es "la irracionalidad de lo racionalizado, que es, a la vez la ineficiencia de la eficiencia” (Hinkelammert, 2005, p. 23). A la eficiencia y la racionalidad económica se les consideran los aportes de la competitividad, y ambas son transformadas en los valores supremos. Esta competitividad borra de la conciencia el sentido de la realidad, pues 
provoca que se perciba como "realidad virtual”. El maíz o el trigo son producidos si son competitivos, no porque alimenten; una pieza de ropa no se fabrica, aunque caliente y dé abrigo, si su producción no es competitiva. Con esta realidad virtual, según la cual todo tiene su criterio en la competitividad, desaparece el valor de uso de las cosas. No obstante, esto se extiende a todas las facetas de la vida, incluyendo aquellas relacionadas con lo jurídico y derechos humanos. Una cultura humana que no produce competitividad tiene que desaparecer, y su desaparición podrá ser interpretada como un devenir natural de los acontecimientos y por el "ejercicio de la libertad" de sus miembros que optaron por dejar de utilizar, por ejemplo, su lengua (es más competitivo hablar inglés que ñañú, por ejemplo); o, igualmente desde este criterio, se ha de considerar que las transformaciones sociales que no aumenten la competitividad no deben realizarse. El dominio de la competitividad no admite acciones frente a los efectos destructores que ella produce; es más, impide siquiera verlos. Significa la afirmación de la Totalidad y la negación del Otro; el encubrimiento del rostro de la víctima, quien lo es por su propia responsabilidad, por no ser “competitivo”. Por eso un sujeto práctico o actuante no es suficiente.

Contrario a la racionalidad medio-fin, Hinkelammert señala que la vida del actor no puede ser un fin, dado que no puede ser tratada como un fin en competencia con otros. Quien elige la muerte, elige la disolución de todos los fines posibles. La vida es la posibilidad de tener fines, y sin embargo, no es un fin. Por eso, si abordamos al actor como un ser vivo que se enfrenta a sus relaciones medio-fin, entonces lo miramos como sujeto. El actor, antes de ser actor, es sujeto humano; sólo se transforma en actor cuando ha decidido sobre el fin y calcula los medios, incluyendo en estos su propia actividad. La racionalidad reproductiva es la propia del sujeto vivo. Para poder enfocar esta racionalidad, debemos asumir al actor más allá de sus relaciones medio-fin; percibirlo como sujeto y, por tanto, no como un fin sino condición de la posibilidad de los fines. El ser humano como sujeto vivo concibe fines y se refiere al conjunto de sus fines posi- 
bles. Pero no puede realizar todos los fines que bajo un cálculo medio-fin parecen posibles; por lo menos debe excluir aquellos fines cuya realización atenta contra su posibilidad de vivir. Si bien el sujeto determina sus fines, no puede desconocer la materialidad de la historia, como señala Ellacuría (1999, p. 55 et seq.). De ahí que el sujeto esté “atado” al circuito natural de la vida humana que es condición de posibilidad de su propia vida.

El criterio de vida o muerte se convierte en el criterio en última instancia. La racionalidad medio-fin pierde legitimidad en cada caso en el que ella entra en contradicción performativa con la racionalidad reproductiva; aquella racionalidad es una racionalidad subordinada a la vida. La irracionalidad de lo racionalizado no es otra cosa que la evidencia de esta contradicción performativa. Como señala Hinkelammert, "[11]a racionalidad medio-fin aplasta la vida humana (y de la naturaleza), lo que evidencia su carácter potencialmente irracional” (Hinkelammert, 2005, p. 49).

La racionalidad del sujeto vivo se enfrenta a la pretensión de mostrar como racionales las acciones que producen muerte. Hinkelammert denuncia la desorientación del mercado y del pensamiento sobre él en relación con la racionalidad reproductiva. Ante el criterio del mercado todas las acciones medio-fin son igualmente racionales, aunque desde la racionalidad reproductiva sean destructoras. Por tanto, las actividades devastadoras de la vida son promovidas por el mercado al igual que las actividades compatibles: "Cortar la rama del árbol sobre la que el actor se halla sentado, es tan racional como cortar cualquier otra”. Se genera entonces una tendencia inevitable del mercado hacia la destrucción en términos de la racionalidad reproductiva; se trata de la muerte tanto de los seres humanos como de la naturaleza: "Esta tendencia destructiva es la irracionalidad de lo racionalizado" (Hinkelammert, 2005, p. 53). Ahora bien, esta tendencia a la destrucción no es necesariamente la finalidad de nadie, sino que resulta de la propia racionalidad medio-fin y por constituirse en una totalidad. El sistema coordinador de la división social del 
trabajo - el mercado - la hace surgir. Podrán tratarse de efectos externos para la racionalidad medio-fin, pero son indiscutiblemente internos para la vida y para la racionalidad reproductiva.

No obstante, cuando la racionalidad medio-fin pretende totalizarse, la racionalidad reproductiva no deja de existir y sigue haciéndose presente. Esta racionalidad no es una postura idealista, sino que responde a una exigencia material, al enfrentamiento del ser humano con la materialidad de la realidad histórica; por tanto, se le asume para preservar la vida o se le soslaya para producir muerte. Cuando más se niega esta racionalidad, aumentan las situaciones que imposibilitan la satisfacción de necesidades, tales como el desempleo, la violencia, el subdesarrollo, la pauperización, etc. Entonces, como señala Hinkelammert, estas insatisfacciones se hacen sentir como exigencias y protestas, pero además “donde no hay protesta posible, como en el caso de la naturaleza destruida, la ausencia de la racionalidad reproductiva se hace presente por las crisis ambientales. (...) Y donde la protesta social no es posible, la ausencia de racionalidad se hace sentir en las crisis de la convivencia, las migraciones, la descomposición social, el crimen y la corrupción” (Hinkelammert, 2005, p. 57).

De lo anterior se desprende la relación del sujeto vivo con el sujeto de la praxis de liberación. La praxis que busca la liberación integral ha de tener como momento material y objetivo la satisfacción de las necesidades de las víctimas; la transformación del sistema y la generación de una nueva institucionalidad deben de tener como objetivo posibilitar la vida y evitar la muerte (Hinkelammert, 2002, p. 338).

La toma de consciencia de la víctima para generar una comunidad y constituirse en una subjetividad emergente que genera "nuevos derechos" tiene como momento inicial el enfrentamiento ante la muerte. Si el aprendizaje de la razón medio-fin es descrito como un aprendizaje de prueba y error, en cambio, el aprendizaje de la racionalidad reproductiva es diferente. Señala Hinkelammert que es un aprendizaje que se enfrenta 
a la muerte para evitarla; busca evitar el derrumbe de todos los fines con la muerte. Se persigue afirmar la vida y entonces el esfuerzo de evitar aquello que la amenace; se trata de un aprendizaje negativo. La praxis de liberación surge, en este contexto, como consecuencia de la experiencia, por parte de las víctimas, de las distorsiones que el mercado produce en la vida y en la naturaleza. Además, la afirmación de la vida no es un fin sino un proyecto: el conservarse como sujeto que puede tener fines. Es así como se genera una conciencia generadora de praxis de liberación: "Se trata de conservar la vida del actor, y no de realizar algún fin positivo mediante una gama de alternativas de la acción por probar. Este aprendizaje en la lógica de la racionalidad reproductiva se refiere a un futuro desconocido con la posibilidad del fracaso. De ahí que los valores implícitos de este aprendizaje son diferentes: de solidaridad; de respeto a la vida propia y a la de los otros, incluyendo a la propia naturaleza; de cuidado y sabiduría. Son valores que relativizan la racionalidad medio-fin y la transforman en racionalidad secundaria. Su relativización es, asimismo, cuestión de vida y muerte” (Hinkelammert, 2005, p. 66-67).

Si bien la comunidad de víctimas toma conciencia y se organiza, generando un consenso para guiar su praxis (principio formal), éste debe tener como proyecto - y a la vez como límite - el desarrollo de la vida (principio material). El sujeto tiene un horizonte objetivo que es de vida y muerte (Hinkelammert, 2005, p. 70). Si no contara con ese horizonte no sería un sujeto vivo; podría en cambio pretender ser un actor de la racionalidad medio-fin que no tiene como límite la vida y llega a generar, como hemos visto, el suicidio.

Quedarse únicamente con el criterio de la producción de vida, del sujeto vivo, como fundamento de derechos humanos correría el riesgo, entre otros, de terminar defendiendo un individualismo justificador de un egoísmo que afirmase un imperativo "sálvase quien pueda" o "viva quien pueda vivir”. Por eso es necesario completar este fundamento con 
el fundamento de la alteridad y de la praxis de liberación. En este sentido, Hinkelammert señala que "[e]l quererse salvar no es suficiente, si bien es condición necesaria. A partir de esta situación, toda relación humana tiene que ser reenfocada. No hay salida, excepto por un reconocimiento mutuo entre sujetos que, a partir de este reconocimiento, someten todo el circuito medio-fin a la satisfacción de sus necesidades. Si se parte de este reconocimiento, es necesaria una solidaridad que sólo es posible si este la sustenta" (Hinkelammert, 2005, p. 68-69). El sujeto se hace sujeto por la afirmación de su vida, pero esta subjetividad se complementa con la afirmación de la vida del otro.

El otro aparece con claridad en las crisis de los sistemas que causan muerte: "Surge así en y ante los sistemas, en los diagramas del Poder, en los lugares standard de enunciación, de pronto, por dichas situaciones críticas, el Otro que el sistema, el rostro del oprimido o excluido, la víctima no-intencional como efecto de la lógica performativa del todo formal racionalizado, mostrando su irracionalidad desde la vida negada de la víctima” (Dussel, 1998, p. 523).

\section{CONCLUSIÓN}

A partir de los conceptos y categorías de la FL es posible construir un fundamento de derechos humanos basado en tres pilares: la alteridad, la praxis de liberación y la producción de vida. Esta fundamentación busca superar el etnocentrismo y el monoculturalismo desde el que se ha conformado la mayoría de las fundamentaciones, que a la par niega el pluralismo cultural y rechaza la posibilidad de una construcción intercultural y descolonizadora de los derechos humanos.

Sin negar la subjetividad como elemento esencial de derechos humanos, la FL la abre a la pluralidad cultural y a las luchas históricas llevadas a cabo por los diversos pueblos oprimidos del planeta; por eso, se trata de un sujeto inter-subjetivo, que desarrolla una praxis de liberación para juridificar las necesidades y acceder a los bienes para la producción, reproducción y desarrollo de la vida. Para la FL, derechos humanos deben 
tener al criterio de vida o muerte como de última instancia. La racionalidad medio-fin pierde legitimidad en cada caso en el que ella entra en contradicción performativa con la racionalidad reproductiva; aquella racionalidad es una racionalidad subordinada a la vida.

La fundamentación propuesta significa un retorno del sujeto, pero no del sujeto metafísico, sino del sujeto viviente, corporal, intersubjetivo y práxico, como un horizonte filosófico para una crítica de la globalización neoliberal. Es decir, la praxis se realiza por una comunidad de víctimas -que se constituye en un sujeto intersubjetivo- que busca, ejerciendo el derecho a generar derechos, subvertir el sistema que le niega la satisfacción de necesidades para la producción y reproducción de vida, y dar paso a un nuevo sistema. Por eso la praxis es un hecho más radical que el estado o la "naturaleza humana", en cuanto a la búsqueda de fundamentos de derechos humanos. Rechaza el dogmatismo, el etnocéntrico y el historicismo, sino que defiende la necesidad del sujeto, pero no del sujeto individual y abstracto de la Modernidad hegemónica, sino el sujeto intersubjetivo que se constituye a través de la voluntad de liberación de las víctimas reunidas y organizadas en comunidad.

\section{REFERENCIAS}

DE LA TORRE RANGEL, Jesús Antonio. Apuntes para una introducción filosófica al derecho. México: Porrúa, 2007.

DUSSEL, Enrique. Ética de la liberación. En la edad de la globalización y de la exclusión. Madrid: Trotta, 1998.

. Filosofía de la liberación. Bogotá: Nueva América, 1996.

. Veinte tesis de politica. México: Siglo XXI, 2006.

ELLACURÍA, Ignacio. En torno al concepto y a la idea de liberación. In: Escritos Teológicos. San Salvador: UCA Editores, 2000. Tomo I.

Respuesta a CETRAL [Mayorías oprimidas, reivindicaciones indígenas en Centroamérica y el problema de los derechos humanos]. In: SENENT, Juan Antonio (Ed.). La lucha por la justicia. Selección de textos de Ignacio Ellacuría (1969-1989). Bilbao: Universidad de Deusto, Bilbao, 2012. 
Filosofía de la realidad histórica. San Salvador: UCA Editores, 1999.

GALLARDO, Helio. Teoría crítica: Matriz y posibilidad de derechos humanos. Murcia: DSR, 2008.

GARCÍA RUIZ, Pedro Enrique. Filosofía de la liberación. Una aproximación al pensamiento de Enrique Dussel. México: Dríada, 2003.

GONZÁLEZ, Antonio. "Prólogo”. In: ELLACURÍA, Ignacio. Filosofia de la realidad histórica. San Salvador: UCA Editores, 1999.

HINKELAMMERT, Franz. Crítica de la razón utópica. Bilbao: Desclée de Brouwer, 2002.

. El sujeto y la ley. El retorno del sujeto reprimido. Heredia de Costa Rica: Euna, 2005.

QUIJANO, Aníbal. Colonialidad del poder y clasificación social. In: Journal of World-Systems Research, VI, 2, summer/fall 2000, Special issue: Festchrift for Immanuel Wallerstein - Part I.

SALAMANCA, Antonio. Filosofía de la revolución. Filosofía para el socialismo en el siglo XXI. San Luis Potosí: UASLP-CEDH, 2008.

Yo soy guardián mundial de mi hermano. Hacia la universalización ética de la opción por el pobre desde el pensamiento de K. O. Apel, E. Dussel y X. Zubiri. Frankfurt: IKO, 2003.

SAMOUR, Héctor. Filosofía y libertad. In: CARDENAL, Rodolfo; SOBRINO, Jon (Coord.). Ignacio Ellacuría. Aquella libertad esclarecida. Santander: Sal Terrae, 1999.

SANTOS, Boaventura de Sousa. Sociología jurídica crítica. Para un nuevo sentido común en el derecho. Madrid-Bogotá: Trotta-ILSA, 2009.

WOLKMER, Antonio Carlos. Bases éticas para una juridicidad alternativa. In: DE LA TORRE RANGEL, Jesús Antonio (Coord.). Derecho alternativo y crítica jurídica. México: UAA-ITESO-Porrúa, 2002.

Recebido em: 28/5/2015

Aceito em: 10/6/2015 